\title{
Assessment of resilience and coping in undergraduate medical students: A need of the day
}

\author{
Abhijeet Faye ${ }^{1}$, Rahul Tadke ${ }^{2}$, Sushil Gawande ${ }^{3}$, Vivek Kirpekar ${ }^{4}$, Sudhir Bhave ${ }^{5}$, Abhijit Pakhare ${ }^{6}$, Deepika \\ Singh $^{7}$, Jeet Nadpara ${ }^{8}$ \\ ${ }^{1,6}$ Assistant Professor, ${ }^{2,3}$ Associate Professor, ${ }^{4}$ Professor \& HOD, ${ }^{5}$ Professor, ${ }^{7}$ Senior Resident, ${ }^{8}$ Ex Junior Resident, \\ $\mathbf{1 , 2 , 3 , 4 , 5 , 7 , 8}$ Dept. of Psychiatry, NKP Salve Institute of Medical Sciences, Nagpur, Maharashtra, ${ }^{6}$ Dept. of Preventive \& Social \\ Medicine, All India Institute of Medical Sciences, Bhopal, Madhya Pradesh, India
}

Corresponding Author:

Email: abhijeetfaye12@gmail.com

\begin{abstract}
Introduction: M.B.B.S. (Bachelor of Medicine, Bachelor of Surgery) is a challenging period for personal, academic \& professional growth of a student. Resilience, the ability to regain original strengths after facing stressful situation is important while dealing with the challenges during M.B.B.S. course. Type of coping can affect resilience. This study aims to assess the resilience in M.B.B.S. students and find the correlation with coping.

Materials and Methods: A cross-sectional study was carried out on consecutively selected 250 M.B.B.S. students. Participants were interviewed with self-reporting questionnaires. Data was collected using semi-structured proforma, resilience scale and mechanisms of coping scale. Statistical analysis was done using mean, standard deviation, chi square test, $t$ test, Pearson's correlation, regression analysis and ANOVA wherever needed.

Result: Mean resilience score was 5.02 with no significant gender differences. Resilience score was significantly higher in first \& second year students and interns. Students with higher resilience score were using problem solving as a major coping. Participants with very good relationship with their family, colleagues and teachers were significantly more resilient. Those having addiction of any sort had significantly low score on resilience and problem solving coping. Participants requiring longer time to come out of stressful situation had lower score on resilience. Participants facing a stressful life situation had significantly less score on problem solving.

Conclusion: Resilience is positively influenced by problem solving, better relationship with others \& less academic stress. It is negatively influenced by emotion based coping, exposure to stressful situation, need of longer time to recover, addiction and higher academic stress.
\end{abstract}

Keywords: Resilience, Coping, M.B.B.S. students.

\section{Introduction}

Medical under graduate course is considered as very vast \& exhaustive and the period of MBBS being stressful for the students. ${ }^{1}$ Medical school is a challenging experience during which students undergo a personal change and professional growth. The challenges they face during this period are varied and unique to each student's context and experience. These challenges can be personal, academic, professional or social. Some of the factors responsible for stress in medical students include being away from home for the first time which implies leaving all previously learned support systems of parents, siblings and school friends, taking responsibilities for own needs, higher academic competition, multiple exams, changing pattern of exams, burden of Post-graduate entrance exam, difficulty in time management and more importantly constant attempt to be clinically competent. There are many studies in the literature focusing on assessment of burnout, depression, phobias or other psychopathology in medical undergraduate students ${ }^{2-3}$ but the factors responsible to build the roots of positive mental health in them are seldom studied.

Resilience is a dynamic process by which individuals show positive adaptation even when they experience significant trauma or adversity. ${ }^{4}$ It's an ability to bounce back when encountered with stress or trauma, sometimes even growing from the experience. ${ }^{5}$ In other words it is the positive capacity to cope with stress. Resilience is required for academic success, to overcome challenges during clinical training and for coping positively with stress in professional life. ${ }^{6}$ Resilient students report greater wellbeing including a positive outlook about their learning environment, good quality of life and academic success. ${ }^{7-8}$

Coping is a process by which an individual maintains the equilibrium of one's emotional states while dealing with stressful situations. It can be viewed as a stabilizing factor that helps individuals in maintaining psychosocial adaptation during any stressful event. Studies have shown that higher levels of coping skill are associated with higher positive adjustment ${ }^{9}$ and less symptoms of burnout. ${ }^{10}$ Broadly there are two major type of coping strategies; problem focused coping and emotion focused coping. Problem-focused coping is, working actively to alleviate the stressful personenvironment relationship by focusing on 'changing the circumstances' whereas emotion-focused coping, involves 'attempts to regulate internal emotional consequences' of stressful or potentially stressful 
situation instead of changing the situation itself. This coping strategy involves thoughts or actions that relieve or reduce the emotional impact of stress. ${ }^{11}$

It is important for a medical student to have appropriate coping skills to handle any stress they encounter during their MBBS studies, as failure to resolve stress can lead to serious professional and personal consequences ${ }^{12}$ in long term. Resilience, as a quality to positively deal with adverse conditions and keep oneself moving on, is also important in this context. During medical training it is important to find out students with low resilience or inadequate/impaired coping as they are at risk of developing emotional problems like burnout, depression or adjustment disorder.

With this background, this study was conducted to assess the resilience and coping skills in MBBS students and to find the correlation between them.

\section{Materials and Methods Study design}

We conducted this cross sectional study in a medical college recognized for undergraduate and post-graduate studies. The undergraduate curriculum of M.B.B.S. (Bachelor of Medicine and Bachelor of Surgery) under the medical university includes 4.5 years of teaching and one year of rotatory internship. Thus the course is divided in to first year, second year, third year, final year and internship.

\section{Sampling and data collection}

The study protocol was approved by institutional Ethics committee (institutional review board) \& departmental permission were taken. After completion of the study the manuscript was reviewed from ethics committee. In this study, 250 students participated. Students were approached in their respective lectures/classes. Year wise, out of various lectures of various teachers across the subjects of that year, one lecture was randomly selected. After the permission of concerned teacher 30 minute slot (of one hour lecture) was considered. Authors explained the students about purpose of the study and option of not participating in the study was also given to them. The study proforma which also included informed consent were distributed in the class. From first year Physiology lecture there were 37 participants, second year Microbiology lecture there were 88 participants, third year Ear, Nose and Throat (ENT) lecture, 30 participants and final year Surgery lecture, 79 participants were willing and completed the proforma. Regarding interns, a random medicine posting was considered and 16 of them consented and completed the proforma. The study was carried out over a period of 12 months (June 2016 to May 2017).

\section{Tools}

We assessed the students using 1) self-reported semi structured proforma which included questions regarding socio-demographic data, relationship history, academic details and personal profile. This also included detachable consent form. Confidentiality was maintained by using only the proforma number in the data analysis; 2) Resilience scale $^{\mathbf{1 3}}$ - The personality characteristic of resilience is assessed using this 15 -item Resilience Scale (RS). The RS used in this study is a modification of Wagnild and Young's (1993) 25-item RS. This modified scale consists of positively stated selfdescriptions to be responded on a 7-point Likert-type response scale, ranging from 1 (Strongly Agree) to 7 (Strongly Disagree). Overall resilience can be determined by totaling the respondents' responses and then dividing the sum by the number of items to obtain a mean resilience score. These responses can then be recoded, so that a high score will indicate a high level of resilience, with 7 being the maximum possible score. The modified 15-item RS has been found to have an alpha of 0.91 when used in a study of 41 adults taking part in an Outdoor Education Program. ${ }^{14}$ Concurrent validity for the original RS has also been demonstrated in various studies by obtaining significant correlations between the RS and measures of constructs that are theoretically linked with resilience, including morale, life satisfaction, stress, self-esteem, depression and health. The 15-item RS has displayed a Cronbach's alpha level ranging from 0.85 (Time One administration) to 0.90 (Time Two administration), thus reflecting the high internal consistency of this scale 3) Mechanisms of coping scale ${ }^{15}$ - devised by Dr. Rajesh Parikh, is a 30item instrument derived from the "Ways of Coping Scale" by Folkman and Lazarus. Selected items of the original scale as well as 6 items relating to Fatalism are incorporated. The 30 items are divided into five factors that relate to five individual ways of coping viz. Escape Avoidance, Fatalism, Expressive Action, Problem Solving and Passivity. After administering the scale, the scores are computed for each of the five factors. Then mean factor score can be calculated. The averages of these scores can then be determined across the subjects. This is a time-tested method of scoring coping data. ${ }^{16}$

It took approximately 20 minutes to complete the proforma for each participant.

\section{Statistical Analysis}

Authors collected the data and analysed it using statistical tests of mean, standard deviation, frequency, chi square test, t test, Pearson's correlation, regression analysis and ANOVA wherever needed. A p value of less than 0.05 was considered significant. 


\section{Results}

Table 1: Demographic factors

\begin{tabular}{|l|l|c|c|}
\hline \multirow{4}{*}{ Gender } & Female & 130 & $52.0 \%$ \\
\cline { 2 - 4 } & Mal & 120 & $48.0 \%$ \\
\hline Residence & Local & 142 & $56.8 \%$ \\
\cline { 2 - 4 } & Outside & 108 & $43.2 \%$ \\
\hline \multirow{5}{*}{ Year of MBBS stay } & At Hostel & 132 & $52.8 \%$ \\
\cline { 2 - 4 } & $\begin{array}{l}\text { With } \\
\text { Parents }\end{array}$ & 96 & $38.4 \%$ \\
\cline { 2 - 4 } & $\begin{array}{l}\text { As Paying } \\
\text { guest }\end{array}$ & 10 & $4.0 \%$ \\
\cline { 2 - 4 } & $\begin{array}{l}\text { With } \\
\text { Relatives }\end{array}$ & 12 & $4.8 \%$ \\
\cline { 2 - 4 } & 1st Year & 37 & $14.8 \%$ \\
\cline { 2 - 4 } & 2nd year & 88 & $35.2 \%$ \\
\cline { 2 - 4 } & 3rd Year & 30 & $12.0 \%$ \\
\cline { 2 - 4 } & Final & 79 & $31.6 \%$ \\
\cline { 2 - 4 } & Intern & 16 & $6.4 \%$ \\
\hline Marital status & Married & 2 & $0.8 \%$ \\
\cline { 2 - 4 } & Unmarried & 248 & $99.2 \%$ \\
\hline \multirow{3}{*}{$\begin{array}{l}\text { Occupation of } \\
\text { parents }\end{array}$} & Business & 77 & $30.8 \%$ \\
\cline { 2 - 4 } & Doctor & 37 & $14.8 \%$ \\
\cline { 2 - 4 } & Engineer & 2 & $0.8 \%$ \\
\cline { 2 - 4 } & Farmer & 3 & $1.2 \%$ \\
\cline { 2 - 4 } & Job & 131 & $52.4 \%$ \\
\hline Family type & Joint & 68 & $27.2 \%$ \\
\cline { 2 - 4 } & Nuclear & 182 & $72.8 \%$ \\
\hline
\end{tabular}

Demographic details are as described in the table 1.

Out of 250 participants $43.2 \%$ mentioned that they study 11-20 hours per week, $28.4 \%$ were studying $<10$ hours/week whereas $20 \%$ said they study for 21-30 hours/week. $39.2 \%$ of the participants spent $41-50$ hours/week in sleeping, 26.8\% were sleeping for 31-40 hours/week whereas $16 \%$ were sleeping for just less than 30 hours/week. On enquiry in to the recreational activities $48 \%$ of the participants said that they have a very little time to spend on recreation (less than 10 hours/week) and only $10 \%$ said they manage to spend 21-30 hours/week for recreation. 74.8\% of the participants were spending less than 5 hours for exercise.

Around $50 \%$ of the participants had not attended any communications skills enhancing workshop or programmes and $70.4 \%$ never underwent any stress management training till the date of interview. 53.2\% were facing some stressful life situation like financial crisis, chronically and severely ill close family member, interpersonal problem with family members, etc. $15.6 \%$ admitted having some or the other substance related addiction. Most of the participants had good relations with family, colleagues and teachers. $53.6 \%$ of the students admitted that they need more time for their academic activities on the other hand $48.4 \%$ agreed that they usually need more time than needed to come out of any stressful condition (Table 2).

\section{Table 2: Profession related details}

\begin{tabular}{|c|c|c|c|}
\hline $\begin{array}{l}\text { Profession related } \\
\text { factors }\end{array}$ & & $\mathbf{N}$ & $\%$ \\
\hline \multirow[t]{4}{*}{ Study hours/week } & $<10$ Hours & 71 & $28.4 \%$ \\
\hline & 11-20 Hours & 108 & $43.2 \%$ \\
\hline & 21-30 Hours & 50 & $20.0 \%$ \\
\hline & $>40$ Hours & 21 & $8.4 \%$ \\
\hline \multirow[t]{4}{*}{ Sleep hours/week } & $<30$ Hours & 40 & $16.0 \%$ \\
\hline & 31-40 Hours & 67 & $26.8 \%$ \\
\hline & 41-50 Hours & 98 & $39.2 \%$ \\
\hline & $>50$ Hours & 45 & $18.0 \%$ \\
\hline \multirow{4}{*}{$\begin{array}{l}\text { Time spent on } \\
\text { recreation/week }\end{array}$} & $<10$ Hours & 120 & $48.0 \%$ \\
\hline & 11-20 Hours & 85 & $34 \%$ \\
\hline & 21-30 Hours & 25 & $10.0 \%$ \\
\hline & $>30$ Hours & 20 & $8.0 \%$ \\
\hline \multirow{4}{*}{$\begin{array}{l}\text { Time spent on } \\
\text { exercise/week }\end{array}$} & $<1$ Hour & 92 & $36.8 \%$ \\
\hline & 1-5 Hours & 95 & $38.0 \%$ \\
\hline & 5-10 Hours & 46 & $18.4 \%$ \\
\hline & $>10$ Hours & 17 & $6.8 \%$ \\
\hline \multirow{2}{*}{$\begin{array}{l}\text { Whether attended } \\
\text { Communication skills } \\
\text { workshop }\end{array}$} & No & 126 & $50.4 \%$ \\
\hline & Yes & 124 & $49.6 \%$ \\
\hline \multirow{2}{*}{$\begin{array}{l}\text { Whether attended } \\
\text { Stress management } \\
\text { workshop }\end{array}$} & No & 176 & $70.4 \%$ \\
\hline & Yes & 74 & $29.6 \%$ \\
\hline \multirow{2}{*}{$\begin{array}{l}\text { Whether facing } \\
\text { Stressful life situation }\end{array}$} & No & 117 & $46.8 \%$ \\
\hline & Yes & 133 & $53.2 \%$ \\
\hline
\end{tabular}




\begin{tabular}{|l|c|c|c|}
\hline Presence of addiction & No & 211 & $84.4 \%$ \\
\cline { 2 - 4 } & Yes & 39 & $15.6 \%$ \\
\hline Relations with \\
colleagues & Average & 34 & $13.6 \%$ \\
\cline { 2 - 4 } & Good & 112 & $44.8 \%$ \\
\cline { 2 - 4 } & Poor & 14 & $5.6 \%$ \\
\cline { 2 - 4 } & Very good & 90 & $36.0 \%$ \\
\hline \multirow{4}{*}{$\begin{array}{l}\text { Relations with } \\
\text { teachers }\end{array}$} & Average & 70 & $28.0 \%$ \\
\cline { 2 - 4 } & Good & 97 & $38.8 \%$ \\
\cline { 2 - 4 } & Poor & 25 & $10.0 \%$ \\
\cline { 2 - 4 } & Very good & 58 & $23.2 \%$ \\
\hline Relations with family & Average & 17 & $6.8 \%$ \\
\cline { 2 - 4 } & Good & 70 & $28.0 \%$ \\
\cline { 2 - 4 } & poor & 7 & $2.8 \%$ \\
\cline { 2 - 4 } & Very good & 156 & $62.4 \%$ \\
\hline \multirow{4}{*}{$\begin{array}{l}\text { Need of more time to } \\
\text { come out of stress }\end{array}$} & No & 129 & $51.6 \%$ \\
\cline { 2 - 4 } & Yes & 121 & $48.4 \%$ \\
\hline
\end{tabular}

\section{Resilience}

Mean score of resilience in male students was 4.96 and that in females was 5.08 with total mean of 5.02 (Fig. $1)$.

On comparing resilience score with respect to year of MBBS, it was found that first year, second year students and interns were significantly more resilient than third and final year students (p-<0.05) (Fig. 2).

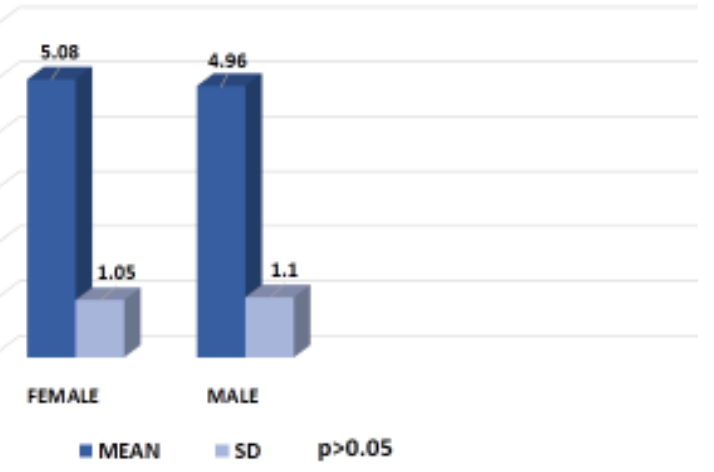

Fig. 1: Resilience mean score and gender

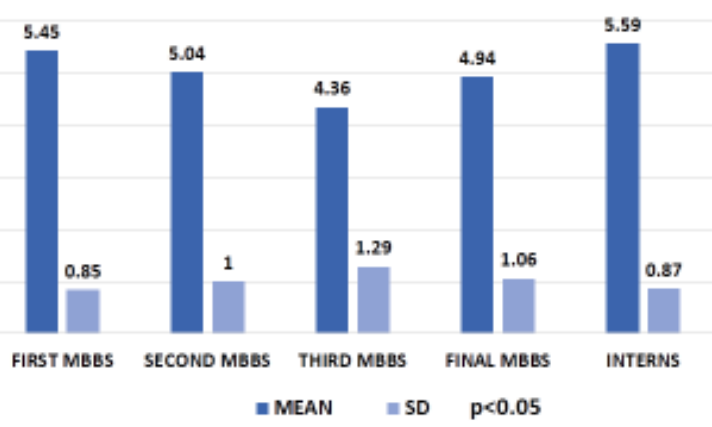

Fig. 2: Resilience mean score \& year of MBBS

\section{Coping mechanisms}

Mean scores for different coping mechanisms based on MOCS were tabulated as given above. Maximum mean score was found for problem based coping i.e. problem solving (mean score 1.89) and expressive action (mean score 1.75) compared to scores for emotion based coping mechanisms (express avoidance, fatalism and passivity) (Table 3).

Table 3: Mean of coping mechanisms

\begin{tabular}{|l|c|c|c|c|c|}
\hline \multicolumn{7}{|c|}{ Mechanisms of coping } \\
\hline & $\begin{array}{c}\text { Express } \\
\text { avoidance }\end{array}$ & Fatalism & $\begin{array}{c}\text { Expressive } \\
\text { action }\end{array}$ & $\begin{array}{c}\text { Problem } \\
\text { solving }\end{array}$ & Passivity \\
\hline Mean & 1.5 & 1.28 & 1.70 & 1.89 & 1.64 \\
\hline SD & 0.6 & 0.69 & 0.55 & 0.62 & 0.56 \\
\hline
\end{tabular}

On correlating resilience and coping mechanisms with the year of M.B.B.S., it was observed that resilience was significantly more in the participants using problem solving as a major coping strategy $(\mathrm{p}-<0.01)$. In second year MBBS students, score on express avoidance subscale was also significantly higher $(\mathrm{P}<0.05)$ whereas in final year MBBS students passivity score was significantly higher along with high score on problem solving mechanism. No significant relation was found between resilience and coping strategies in interns (Table 4). Comparing resilience with mean of coping mechanisms in whole sample (not M.B.B.S. year wise) showed significantly negative correlation between resilience \& Fatalism with $\mathrm{p}$ value $<0.05$ (more the resilience less the use of fatalism coping strategy). 
Table 4: MBBS Year wise correlation between resilience and coping mechanisms

\begin{tabular}{|c|c|c|c|c|c|c|}
\hline \multicolumn{7}{|c|}{ First year MBBS } \\
\hline & & $\begin{array}{c}\text { Express } \\
\text { avoidance }\end{array}$ & Fatalism & $\begin{array}{l}\text { Expressive } \\
\text { action }\end{array}$ & $\begin{array}{c}\text { Problem } \\
\text { solving }\end{array}$ & Passivity \\
\hline \multirow[t]{2}{*}{ Resilience } & $\begin{array}{l}\text { Pearson } \\
\text { Correlation }\end{array}$ & 0.014 & -0.255 & 0.322 & $0.435^{* * *}$ & 0.021 \\
\hline & Sig. (2-tailed) & 0.936 & 0.128 & 0.052 & 0.007 & 0.900 \\
\hline \multicolumn{7}{|c|}{ Second year MBBS } \\
\hline \multirow[t]{2}{*}{ Resilience } & $\begin{array}{l}\text { Pearson } \\
\text { Correlation }\end{array}$ & $.240^{*}$ & -.130 & .115 & $.300^{* *}$ & .029 \\
\hline & Sig. (2-tailed) & .024 & .226 & .284 & .004 & .790 \\
\hline \multicolumn{7}{|c|}{ Third year MBBS } \\
\hline \multirow[t]{2}{*}{ Resilience } & $\begin{array}{l}\text { Pearson } \\
\text { Correlation }\end{array}$ & .231 & .034 & .315 & $.475^{* *}$ & .218 \\
\hline & Sig. (2-tailed) & .219 & .859 & .090 & .008 & .248 \\
\hline \multicolumn{7}{|c|}{ Final year MBBS } \\
\hline \multirow[t]{2}{*}{ Resilience } & $\begin{array}{l}\text { Pearson } \\
\text { Correlation }\end{array}$ & .166 & -.041 & .170 & $.690^{* *}$ & $.339^{* *}$ \\
\hline & Sig. (2-tailed) & .144 & .717 & .133 & .000 & .002 \\
\hline \multicolumn{7}{|c|}{ Interns } \\
\hline \multirow[t]{2}{*}{ Resilience } & $\begin{array}{l}\text { Pearson } \\
\text { Correlation }\end{array}$ & -.023 & .169 & .407 & .470 & .413 \\
\hline & Sig. (2-tailed) & .933 & .531 & .118 & .066 & .111 \\
\hline
\end{tabular}

Resilience score was also found to be significantly higher in those with good or very good interpersonal relation with their family members $(\mathrm{p}-<0.001)$, colleagues and teachers $(\mathrm{p}-0.004)$ (Table 5).

Table 5: Resilience and interpersonal relation

\begin{tabular}{|l|c|c|c|c|}
\hline \multirow{4}{*}{$\begin{array}{l}\text { Relations with } \\
\text { colleagues }\end{array}$} & & \multicolumn{3}{|c|}{ Resilience } \\
\cline { 2 - 4 } & & Mean & SD & p value \\
\cline { 2 - 4 } & Average & 4.73 & 1.10 & \multirow{2}{*}{0.004} \\
\cline { 2 - 4 } & Good & 4.97 & 1.04 & \\
\cline { 2 - 4 } & Poor & 4.43 & 1.42 & \\
\cline { 2 - 4 } & Very good & 5.29 & 0.98 & \\
\hline \multirow{3}{*}{$\begin{array}{l}\text { Relations with } \\
\text { family }\end{array}$} & Average & 3.87 & 1.05 & \multirow{2}{*}{$<0.001$} \\
\cline { 2 - 4 } & Good & 4.87 & 1.06 & \\
\cline { 2 - 4 } & Poor & 4.56 & 0.75 & \\
\cline { 2 - 4 } & Very good & 5.24 & 1.00 & \\
\hline \multirow{3}{*}{$\begin{array}{l}\text { Relations with } \\
\text { teachers }\end{array}$} & Average & 4.76 & 1.11 & \multirow{2}{*}{0.004} \\
\cline { 2 - 4 } & Good & 5.06 & 1.06 & \\
\cline { 2 - 4 } & Poor & 4.75 & 1.05 & \\
\cline { 2 - 4 } & Very good & 5.39 & 0.96 & \\
\hline
\end{tabular}

Resilience score was significantly more in those who chose their profession by the choice of both themselves and their parents.

The score on resilience and problem solving type of coping were significantly low (p-0.014) in participants who admitted that they have substance related addiction, compared to those with no addiction. (Table 6) 
Table 6: Resilience and coping with Addiction

\begin{tabular}{|l|c|c|c|c|c|c|}
\hline \multirow{2}{*}{} & \multicolumn{6}{|c|}{ Addiction (alcohol/other substances) } \\
\cline { 2 - 7 } & Valid N & Mean & $\begin{array}{l}\text { Standard } \\
\text { Deviation }\end{array}$ & Valid N & Mean & $\begin{array}{l}\text { Standard } \\
\text { Deviation }\end{array}$ \\
\cline { 2 - 7 } & 211 & $5.15_{\mathrm{a}}$ & 1.04 & 39 & $4.32_{\mathrm{b}}$ & .98 \\
\hline Resilience & 211 & $1.5_{\mathrm{a}}$ & .6 & 39 & $1.5 \mathrm{a}$ & .5 \\
\hline $\begin{array}{l}\text { Express } \\
\text { avoidance }\end{array}$ & 211 & $1.28_{\mathrm{a}}$ & .71 & 39 & $1.33_{\mathrm{a}}$ & .59 \\
\hline Fatalism & 211 & $1.72_{\mathrm{a}}$ & .56 & 39 & $1.56_{\mathrm{a}}$ & .50 \\
\hline Expressive action & 211 & $1.97_{\mathrm{a}}$ & .61 & 39 & $1.47_{\mathrm{b}}$ & .48 \\
\hline Problem solving & 211 & $1.65_{\mathrm{a}}$ & .58 & 39 & $1.59_{\mathrm{a}}$ & .46 \\
\hline Passivity & & & & & & \\
\hline
\end{tabular}

No statistically significant correlation found on comparing resilience with type of family (joint or nuclear), number of sleep hours and attendance of stress management workshop/communication skills workshop. Participants who agreed that they require more time to come out of stressful situations were found to have less score on resilience $(\mathrm{p}<0.001)$.

Participants who said they are facing a stressful life situation had significantly higher scores on all coping mechanisms $(\mathrm{p}<0.05)$ except problem solving. Students who agreed that they usually require more time to come out of any stressful situation were found having significantly low score on problem solving. No significant correlation was found between coping and attendance of stress management or communication skills workshop.

\section{Discussion}

Medical students who begin their career with high morale and enthusiasm usually experience relatively higher degree of stress which in turn may lead to burnout and depression during the training. They might not seek help because of the associated stigma or avoidance due to lack of awareness. Adaptation to the changed life style and 'high demand' nature of this professional training could be difficult in some of them. It is therefore necessary to analyse how adaptive they are to the stressful situations and how they cope up with the challenges they are exposed to, during their medical training.

More than $70 \%$ were staying in nuclear family which was as per the current trend of family system in urban areas.

Majority (around 3/4 ${ }^{\text {th }}$ ) of the students were doing exercise for less than 5 hours per week which is very less considering their age requirement for exercise. This raises a question of whether this is the outcome of getting less time for self, not inclined for exercises or sports activity or spending more time for less physically exhaustive activities like internet, online games, spending time on social media or television and reading books? Being a professional course, self-study is an important aspect and pattern of recurrent examinations can add to increased amount of study related activities as reflected in the finding of some (8.4\%) students studying more than 40 hours per week. As per the age of the student a sleep of 7-9 hours/day is expected in them making it 50-60 hours/week. ${ }^{17}$ The students in this study were sleeping for less than required and $16 \%$ were unable to sleep even half of it (30 hours/week). Getting less time for recreational activities is common in medical profession. In this study nearly half (48\%) of the students were spending less than 10 hours/week on leisure and recreational activities suggesting that they were getting less time to relax themselves. These factors may contribute to the stress and coping in medical students. Studies have shown that leisure activities can reduce stress in medical school. ${ }^{18}$ Regular exercise and adequate sleep are important for psychological wellbeing and can be considered as supportive factors for good coping. This type of lifestyle in medical students can be one of etiological factors for higher level of burnout and stress in them. ${ }^{3}$

Higher self-efficacy and optimism which are important components of resilience are associated with more active coping behaviour. ${ }^{19}$ Resilient individuals have also been described as having meaningfulness, ${ }^{20}$ confidence, ${ }^{21}$ perseverance, ${ }^{22}$ problem-solving skills ${ }^{20}$ and flexibility. ${ }^{23}$ These skills are important in M.B.B.S. students to make them confident and efficient doctors in future. This makes resilience an important aspect to be studied in this population.

This study showed no significant gender difference in resilience suggesting that gender doesn't play a significant role in relation to resilience. This was similar to the findings of other studies done on M.B.B.S. students ${ }^{24}$ and adolescents. ${ }^{13}$

Resilience score was significantly high in first year $\&$ second year students and interns compared to third and final year students. Third year (part I and II/final) is a year of high academic demands in terms of studies and clinical work which can be stressful to many students resulting in worries, decreased self-confidence and reduced ability to maintain positivity of thoughts and perform effectively. This can be a reason for low scores on resilience in this group. It can also be correlated with the findings by Lazarus who stated that the stressful conditions when viewed by a person as refractory to 
change the emotion-focused coping predominates and when they are appraised as controllable by action, problem-focused coping predominates ${ }^{25}$ which is directly related to higher degree of resilience.

Problem solving coping score was less in second, third and final year M.B.B.S. students compared to first year students and interns. Stress levels are relatively high in third year, during the transition from classrooms to clinical work. The medicine taught in classroom is no longer in theory and the outcome or consequences of the care/medicine given are directly observable in the lives of patients. Students may encounter the clinical experiences as highly rewarding, but it can be challenging if patients' condition worsen. With practice and repeated clinical experiences students develop skills $\&$ clinical acumen and may start seeing every clinical situation as a challenge and opportunity to new learning. This results in more rational and problem based coping which is reflected in this study with high score in interns.

Authors also found that students with very good relations with their colleagues, teachers and family members were significantly more resilient. This can be explained as social and family supports are important factors not only for preserving positive mental health but also for providing and maintaining mental strength to cope up with stressful situations. During MBBS period colleagues are the main source of support $\&$ help with respect to emotional or academic issues. Good relations with them certainly serves as positive factor in coming out of stress. Some studies described other factors like optimism, humor, cognitive flexibility, cognitive explanatory style and reappraisal, religion/spirituality, exercise, capacity to recover from negative events having influence on resilience. ${ }^{26}$

Participants with high scores on resilience also had greater score on problem solving subscale of coping and negative correlation with fatalism. This can be explained as problem based coping is based on rational thinking including analyzing any stressful situation and selfpotentials \& weaknesses and then acting with most practical and feasible way. Such coping helps in early coming out of stressful situation and regaining normal strength at the earliest. Some studies have defined Resilience as "a dynamic capability that can allow person to thrive on challenges given appropriate social and personal contexts ${ }^{27}$ and suggested that positive coping mechanisms such as seeking social support (problem focused coping) are positively associated with resilience.

Students facing a stressful life situation had significantly higher scores on all coping mechanisms except problem solving. Whenever individuals are exposed to any stressful situation, initial emotional responses are usually negative as body and mind takes time to accept and adapt to the situation. Going through the stress is a mixed state of emotions with perceiving the situation initially as the end and no way out. Individuals try to cope up with the situation with emotion based coping like express avoidance, fatalism and passivity but subsequently they realize the temporary nature of the situation, start thinking rationally \& practically, they actively seek help by expressive action and use problem based coping. So, it is possible that individual uses multiple types of coping during stress as in this study. Studies also show that the ability to experience both positive and negative emotions simultaneously when exposed to a stressful situation increases flexibility of thinking and problem solving which can buffer individuals from developing stressinduced adverse consequences. ${ }^{28-29}$ Also those who confessed that they usually require more time to come out of any stressful situation had significantly low score on resilience and problem solving type of coping. This is obvious as resilience itself means bouncing back to original strength while facing any stress. Some researchers found that students who encountered more traumatic events experienced more personal growth, suggestive of resilience ${ }^{30}$ which was contradictory to the findings of our study.

This study also showed that participants with alcohol or other substance addiction had low scores on resilience and problem solving. Literature mentions that addiction is a result of emotion based coping. Individuals with predominantly problem based coping (like problem solving) tend to find constructive and creative solution to deal with stressful situations. Studies ${ }^{31}$ found that individuals who scored high on emotion based coping (fatalism, passivity and express avoidance), used more alcohol while experiencing a negative life event compared to those who scored low on emotion based coping.

We also found that participants who said they chose their profession by the choice of both themselves and their parents scored high on resilience. Getting in to the profession of choice can be a life satisfying event and studies show that medical students who sustained high levels of life satisfaction perceive medical school as less interfering in their social and personal life. Also they less likely use passive, emotion focused coping ${ }^{32}$ which in turn can be the indicator of high resilience.

Burnout, a syndrome of emotional exhaustion, depersonalization and low personal accomplishment causing decreased effectiveness at work place ${ }^{33}$ appears to be the most common form of stress. Hard work and intensity of studying activities during M.B.B.S. course predispose the student to psychological and physical exhaustion which may subsequently result in psychopathology and sometimes even the psychiatric disorders. Anxiety, depression and psychosomatic disorders are found prevalent in medical students ${ }^{34}$ with stress as an important predisposing factor.

Thus it is important to analyze \& enhance the resilience and coping strategies in medical students to make them efficient to deal with stresses that are prevalent throughout the medical training such as uncertainty about the future, economic problems, 
academic concerns and pressure with regard to success. Above factors might favor or precipitate manifestations of psychopathology and increases the necessity to assess college students' mental health. ${ }^{35}$ If interventions (like mentorship program and individual guidance) to increase the resilience and improving coping are planned during M.B.B.S. period, the subsequent serious psychopathology can be prevented.

\section{Conclusion}

It can be concluded from the study that third and final year MBBS students had significantly low resilience compared to others. Problem solving coping was low in second, third and final year students indicating the need for interventions to prepare and help MBBS students during their transition phase from classroom teaching to more demanding clinical skills learning phase. Healthy and favorable relations with family, colleagues \& teachers and problem focused coping were promoting factors for resilience. Facing stressful life situation and requiring more time to come out of it was associated with less use of problem solving coping. Presence of addiction was associated with low resilience and less use of problem focused coping indicating that addiction is a result of poor coping.

It can also be concluded that irrespective of a gender, first year MBBS students, using predominantly problem solving coping, having very good relations with colleagues, family \& teachers and have chosen their profession by choice of themselves and their parents were found to be significantly more resilient. Similarly third and final year MBBS students with no very good relations with family, colleagues or teachers, using predominantly emotion focused coping who agreed that they require more time to come out of stressful situations and had addiction were significantly less resilient. No relation was found between resilience or coping and participation in stress management or communication skills workshops.

\section{Implications}

Resilience can be a key to enhance sustainability of medical students during health care training and to promote improving quality of patient care. Cultivating specific skills, habits and attitudes that promote resilience is possible for medical students and is need of the day. Medical institutes should encourage students to achieve a balance between academics and their social \& personal lives and emphasize on development of healthy coping strategies.

\section{Limitations}

It was a cross sectional study conducted on a specific population, so findings can't be generalized. A longitudinal study at multiple centers with a larger sample size is recommended for future research.

\section{Acknowledgement}

We acknowledge all the teachers (Faculty members) who allowed us to interview the participants and collect data during their lectures. We also acknowledge all the M.B.B.S. students who willingly participated in the study.

\section{Conflict of interest- Nil \\ Source of support/funding-Nil \\ Ethical approval -Approved}

\section{References}

1. Dyrbye LN, Thomas MR, Huntington JL, Lawson KL, Novotny PJ, Sloan JA, et al. Personal life events and medical student burnout: a multicenter study. Acad Med 2006;81(4):374-84.

2. Thompson G, McBride RB, Hosford CC \& Halaas G. Resilience among Medical Students: The Role of Coping Style and Social Support. Teaching and Learning in Medicine 2016;28(2):174-82.

3. Ishak W, Nikravesh R, Lederer S, Perry R, Ogunyemi D, Bernstein C. Burnout in medical students: a systematic review. Clin Teach 2013;10(4):242-5.

4. Luthar SS, Cicchetti D. The construct of resilience: implication for interventions and social policies. Dev Psychopathol. 2000;12(4):857-85.

5. Southwick S, Charney D. The Science of Mastering Life's Greatest Challenges. From book 'Resilience'2012. Cambridge University Press, New York.

6. Greenhill J, Fielke KR, Richards JN, Walker LJ, Walters LK. Towards an understanding of medical student resilience in longitudinal integrated clerkships. BMC Med Educ. 2015;15:137.

7. Dyrbye LN, Power DV, Massie FS, Eacker A, Harper W, Thomas MR, et al. Factors associated with resilience to and recovery from burnout: a prospective, multiinstitutional study of US medical students. Med Educ. 2010;44(10):1016-26.

8. Martin AJ, Marsh HW. Academic resilience and its psychological and educational correlates:a construct validity approach. Psychology in the Schools. 2006;43(3):267-81.

9. Cheng C, Cheung MW. Cognitive processes underlying coping flexibility: Differentiation and integration. J Pers 2005;73:859-86.

10. Gan Y, Shang J, Zhang Y. Coping flexibility and locus of control as predictors of burnout among Chinese college students. Soc Behav Pers 2007;35:1087-98.

11. Fresco DM, Williams NL, Nugent NR. Flexibility and negative affect: Examining the associations of explanatory flexibility and coping flexibility to each other and to depression and anxiety. Cognit Ther Res 2006;30:201-10.

12. Nicholl H, Timmins F. Programme-related stressors among part-time undergraduate nursing students. J Adv Nurs 2005;50:93-100.

13. Skehill CM. Resilience, Coping with an Extended Stay Outdoor Education Program. Honours Thesis, Centre for Applied Psychology, University of Canberra, 2001.

14. Neill JT \& Dias KL. Adventure Education and Resilience: The Double-Edged Sword. Journal of Adventure Education and Outdoor Learning 2001;1(2):35-42.

15. Parikh RM, Quadros T, D' Mello M, Aguiar R, Jain R, Khambatta F et al. Mechanisms of coping and 
psychopathology following Latur earthquake: The profile study. Bombay Psychiatric Bulletin 1993-1995;5:7-18.

16. Hast KF. A comparison of two techniques for scoring episodic coping data. Personality and Individual Differences 1996;21:159-62.

17. Matricciani L, Bin YS, Lallukka T, Kronholm E, Dumuid $\mathrm{D}$, Paquet C, Olds T. Past, present, and future: trends in sleep duration and implications for public health. Sleep Health Journal of the National Sleep Foundation 2017;3:317-23.

18. Shaikh B, Kahloon A, Kazmi M, Khalid H, Nawaz K, Khan N, et al. Students, stress and coping strategies: a case of Pakistani medical school. Educ Health (Abingdon). 2004,17:346-53.

19. Rose M, Fliege H, Hildebrandt M, Schirop T, Klapp BF. The network of psychological variables in patients with diabetes and their importance for quality of life and metabolic control. Diabetes Care 2002;25:35-42.

20. Aroian KJ, Schappler-Morris N, Neary S, Spitzer A, Tran TV. Psychometric evaluation of the Russian Language version of the Resilience Scale. J Nurs Meas 1997;5:15164.

21. Higgins GO. Resilient Adults: Overcoming a Cruel Past. San Francisco: Jossey-Bass;1994.

22. Mrazek PJ, Mrazek DA. Resilience in child maltreatment victims: A conceptual exploration. Child Abuse Negl 1987;11:357-66.

23. Werner E. Risk, resilience and recovery: Perspectives from the Kauai longitudinal study. Dev Psychopathol 1993;5:503-15.

24. Somaiya M, Kolpakwar S, Faye A, Kamath R. Study of mechanisms of coping, resilience and quality of life in medical undergraduates. Indian journal of Social Psychiatry 2015;31(1):19-28.

25. Lazarus RS. From psychological stress to the emotions: A history of changing outlooks. Annu Rev Psychol 1993;44:1-21.

26. Southwick SM, Vythilingam M, Charney DS. The psychobiology of depression and resilience to stress: Implications for prevention and treatment. Annu Rev Clin Psychol 2005;1:255-91.

27. Howe A, Smajdor A, Stockl A. Towards an understanding of resilience and its relevance to medical training. Medical Education 2012;46:349-56.

28. Fredrickson BL. The role of positive emotions in positive psychology: The broaden-and-build theory of positive emotions. American Psychologist 2001;56(3):218-26.

29. Ong AD, Bergeman CS, Bisconti TL, Wallace KA. Psychological resilience, positive emotions, and successful adaptation to stress in later life. Journal of Personality and Social Psychology 2006;91(4):730-49.

30. Haglund ME, aan het Rot M, Cooper NS, Nestadt PS, Muller D, Southwick SM, Charney DS. Resilience in the third year of medical school: a prospective study of the associations between stressful events occurring during clinical rotations and student well-being. Acad Med. 2009;84(2):258-68.

31. Veenstra MY, Lemmens PH, Friesema IH, et al. Coping style mediates impact of stress on alcohol use: A prospective population-based study. Addiction 2007;102(12):1890-8.

32. Kjeldstadli K, Tyssen R, Finset A, Hem E, Gude T, Gronvold NT, et al. Life satisfaction and resilience in medical school - a six-year longitudinal, nationwide and comparative study. BMC Medical Education 2006;6:48.

33. Dyrbye LN, Thomas MR, Massie FS, et al. Burnout and suicidal ideation among U.S. medical students. Ann Intern Med. 2008;149:334-41.
34. González-Ramírez MT, Landero-Hernández R, GarcíaCampayo J. The relationship among depression, anxiety, and somatic symptoms in a sample of university students in northern Mexico. Rev Panam Salud Pública. 2009;25:141-5.

35. Fares J, Tabosh HA, Saadeddin Z, Mouhayyar CE, Aridi H. Stress, Burnout and Coping Strategies in Preclinical Medical Students. N Am J Med Sci 2016;8(2):75-81. 